\title{
Strategies of Repair in EFL Learners' Oral Discourse
}

\author{
Ghaleb Rabab'ah ${ }^{1}$ \\ ${ }^{1}$ Department of Humanities \& Social Sciences, College of Science and General Studies, Alfaisal University, \\ Saudi Arabia \\ Correspondence: Ghaleb Rabab'ah, Department of Humanities \& Social Sciences, College of Science and \\ General Studies, Alfaisal University, P. O Box 50927, Riyadh 11533, Saudi Arabia. E-mail: \\ grababah@alfaisal.edu; ghalebrababah@gmail.com
}

\author{
Received: March 24, 2013 Accepted: May 2, 2013 Online Published: May 8, 2013 \\ doi:10.5539/elt.v6n6p123 URL: http://dx.doi.org/10.5539/elt.v6n6p123
}

\begin{abstract}
This study examines how EFL learners in the non-English speaking communities (Jordan and Germany) handle communication in story-retelling, and uncovers the repair strategies, which they deploy in order to overcome communication breakdowns and pass comprehensible messages to their interlocutors. The study also analyzes factors governing the EFL learners' preferences for employing repair strategies. It examines two repair strategies used by Jordanian and German EFL learners; self-initiated repair and repetition. The participants of this study were volunteer third-year students enrolled in the Linguistics Department at Chemnitz Technical University (Germany) and the University of Jordan (Jordan). Two short stories, selected from 100 free English short stories for ESL learners, were used to elicit data. The results of the analysis revealed that both German and Jordanian non-native speakers of English resort to strategies of repair in order to compensate for their lack of linguistic items or to gain time to retrieve linguistic item(s) and maintain conversation. Moreover, the results indicate that the Jordanian Arabic speaking subjects used strategies of repair more frequently, which was attributed to the fact that they produced more story events, which doubled the number of words in their oral production. Another finding was that repetition was used more frequently than self-initiated repair by both groups. The results of this study may provide some useful insights into syllabus design and English language teaching (ELT).
\end{abstract}

Keywords: communication strategies, self-initiated repair, repetition, discourse analysis, repair strategies, pragmatics, EFL learners

\section{Introduction}

Increasing numbers of students from diverse linguistic and cultural backgrounds have a great interest in studying English as a foreign/second language since English is an international language, the language of the Internet, and the language of business communication worldwide. According to Watterson (2008, p. 378), "The international use of English as a lingua franca (ELF) - i.e. between non-native speakers of different nationalities, in situations where no native English speakers are present - has become an important feature of business, diplomacy, education, and personal relationships around the world".

Hence, non-native speakers are challenged with the inevitable task of communicating successfully with each other, i.e., sending and receiving comprehensible messages. They struggle to transmit a comprehensible message to their interlocutors, and they sometimes fail to do so. Therefore, Leonard (1983) suggests that competent communicators learn to regulate and modify messages within a conversation. Speech modification may entail planning to select appropriate words, reducing the complexity of utterances, or elaborating on a statement for clarification. When individuals do not properly regulate or modify messages, a communication breakdown may occur. Drew (2005) also claims that "It is fundamental in conversation that participants construct or design their talk so as to be understood in the way they wish to be understood" (p. 94).

One way of modifying, organizing and maintaining conversation is by using repair, as a communication strategy. Researchers suggest that using communication strategies to prevent communication breakdowns, and to get a message across to the listener lead to second language learning (Swain, 1985; Rababah, 2007). Such modified speech is referred to as comprehensible output (Swain, 1985). The comprehensible output hypothesis suggests that language is acquired when there is a communication breakdown, and language users are "pushed to use alternative means to get across... the messages... precisely, coherently and appropriately" (Swain, 1985, pp. 
248-249).

Based on previous claims, the present research aims to investigate whether two strategies of repair: repetition and self-initiated repair are used in the oral production of German and Jordanian EFL learners. The study also aims to identify how repair strategies are used by both groups in order to regulate and maintain conversation, pass comprehensible messages to their interlocutors and achieve their communicative goals. In the present research, self-initiated self refer and self-repair are used interchangeably. The findings will hopefully provide insights into how important these strategies are in real life communication, and how they can be integrated into the EFL syllabus.

\section{Literature Review}

One of the common features of spoken discourse is repair, which results from the speakers' recognition of faulty plans. According to Faerch and Kasper (1983), during the planning and execution phases, L2 speakers encounter problems due to their lack of linguistic resources; therefore, they modify their plan and use their existing knowledge, usually consciously, with the intention of sending a comprehensible message and achieving their communicative goal.

Schegloff et al. (1977, p. 361) defined repair as dealing with "recurrent problems in speaking, hearing, and understanding." In addition to linguistic problems (pronunciation, vocabulary, syntax, etc.), it may also relate to acceptability problems, such as saying something wrong in a broad sense, that is untrue, inappropriate or irrelevant (Schegloff, 2007). The particular segment of talk to which the repair is addressed, is called the trouble source or the repairable. Drew (1997: 96) suggests that "self-repair is also a mechanism of remedying mistakes in conversation." Research on repair has identified a variety of repair strategies, namely self-initiation self-repair, other-initiation self-repair, other initiation other repair, repetition, paraphrase, confirmation checks, clarification requests and comprehension checks (Schegloff et al., 1977; Schegloff, 2000; Nagano, 1997; Drew, 1997). The present research will only investigate repetition and self-initiated repair because the present researcher believes that these two are prominent features of daily communication, and that knowing why and how these strategies are used could help Jordanian and German EFL learners become aware of these strategies, which would help them maintain conversation with their interlocutors.

It is evident in second language acquisition research that both native and non-native speakers of English use repair strategies while negotiating meaning in order to understand or make themselves understood. For example, Nagano (1997: 81) in his study on the self-repair of Japanese learners of English concludes that "... the self-repair of Japanese speakers of English is not very different in some ways from that of the L1 speakers in Levelt's study". Research has also shown that repair, which is a language phenomenon, is necessary for keeping communication smooth and accurate, and it has been evident in the literature that language learners are able to employ many repair strategies in second language interaction (Schegloff et al., 1977, Watterson, 2008, Leftheriadou and Badger, 1999, Schegloff et al., 2000, 2007).

\subsection{Self-Initiated Repair}

According to Schegloff et al. (1977), self-initiated self-repair (self-repair) takes the form of initiation with a non-lexical initiator, followed by the repairing segment (p. 376). These non-lexical initiators include cut-offs, lengthening of sounds, and quasi-lexical fillers such as $u h$ and $u m$. In order to repair their errors in problematic talk, language users repeat words and use fillers to gain time and achieve their communicative goal. Schegloff et al. (1977) state that self-initiated and self-completed repair (self-initiated self-repair) occurs when the interlocutor who is responsible for the trouble source both initiates and completes the repair.

The problematic talk 'trouble source' can be defined as an utterance or a part of an utterance that is perceived as problematic by at least one of the interlocutors. The speaker may feel that the utterance did not correspond to what he/she wanted to say, while the hearer may be unable to decode the intended meaning of the utterance. The speaker may also assume that the recipient did not understand the utterance in the right way (Faerch and Kasper, 1982:79).

Self-initiation, self-completed repair is the most common repair strategy used (cf. Schegloff et al., 1977). The speaker makes an error, detects it, cuts off what he/she was saying, and repairs the error. Repairs are signaled through the use of strategies, such as interruption, editing expressions $(\mathrm{er}, \mathrm{em})$ and backtracking. Similarly, Berg (1986: 212) admits that the repair process begins with an error. An error means "all kinds of inadvertent behaviours". Errors are usually detected during the articulation of the problematic word, which is usually signaled by the interruption of the flow of speech by the speaker himself.

Research on the repair of second language learners (e.g., Kranke \& Christison, 1983; Schegloff, 2000) shows preference for self-initiated repair, although variations can be seen in the amount of initiation depending on the 
learner's language level (cf. Krahnke and Christison, 1983). Krahnke and Christison (1983) remark that "... language learners have demonstrated ability to utilize non-language-specific techniques of interaction maintenance which also facilitate their comprehension, and, we can assume, their acquisition of the new language" (p. 234).

\subsection{Repetition}

Repetition is a common strategy whose role in communication could be one of the "most effective strategies for promoting comprehension that a speaker can use" (Hoekje, 1984: 10). Research to date reveals that Arab and German learners of English use self-initiated repair in their oral production (e.g., Rababah, 2001; Rababah and Bulut, 2007; and Rieger, 2003). However, none of these studies has made a comparison between English majors using the same data collection tool. In their investigations of communication strategies used by Arab EFL learners in English and Arabic (Rababah, 2001), and communication strategies of learners of Arabic as a second language (Rababah and Bulut, 2007), the researchers found out that both native and non-native speakers repeated some speech segments to gain more time in order to retrieve the required speech segment, and maintain conversation, and used self-correction when they realized that they had made a mistake.

Rieger (2003, p. 47) states that repetition, which is a type of self-repair is the most common type of repair consisting of a particular set of repair strategies where the repairable and repairing segments occur in the same turn and the repair is performed by the initiator of the repairable. She also concluded that English-German bilinguals resort to repetitions as self-repair strategies differently, depending on the language they speak. She also states that "Repetitions - which are also called recycling - consist of the consecutive usage of the same quasi-lexical or lexical item or items" (p. 51). Rieger (2003) found that "They repeat more pronoun-verb combinations, more personal pronouns, and more prepositions in English than in German, and they recycle more demonstrative pronouns in German than in English". She related these differences to "structural differences in English and German, demonstrating that the structure of a particular language shapes the repair strategies of language users" (p. 47).

As far as narratives and story-telling are concerned, very limited research has tackled repair strategies using story-telling tasks, and these were limited in their scope and aims. In Kernan et al.'s study (1991), narratives of a short film by mentally retarded and non-retarded adults were compared in terms of the structure they exhibited and the self-initiated repairs they contained. The researchers found out that the mentally retarded speakers produced shorter narratives. Wood's study (2006) was also undertaken to identify the uses and functions of formulaic sequences in the development of speech fluency in narrative retelling in English as a Second Language (ESL). Wood found out that the most common feature of story-telling is repetition and use of fillers.

While repair strategies have been studied widely in intracultural and intercultural communication (Schegloff et al, 1977, Schegloff, 2007; Dascal 1999; Tzanne 2000; Bosco et al., 2006; Birkner, et al., 2012), Arab and German learners of English are under-represented in repair strategy research. Very few research studies have been conducted to investigate strategies of repair used by German and Arab EFL English majors. As far as the review of research is concerned, only two studies examined self-repair and repetition (Rieger 2000; 2003). Rieger (2000) in her $\mathrm{PhD}$ dissertation examined the role of language, gender and proficiency of the use of self-repair strategies of English-German bilinguals in informal conversations. Rieger (2003) also examined repetitions as self-repair strategies in English-German conversations. She concluded that repeating one or several lexical items is part of the self-repair organization.

In Jordan, no due attention has been paid to the use of strategies of repair of Jordanian EFL learners, although it is a natural phenomenon in real life conversations. As far as the Jordanian EFL learners are concerned, Rababah's study (2001) revealed that they resort to repetition and self-correction (self-initiated repair) when they are in trouble and they need to fill a gap in communication.

The present study examines how EFL learners in non-English speaking communities, in Jordan and Germany, handle communication, and uncovers the repair strategies they deploy in order for them to pass comprehensible messages to their interlocutors. The study also analyses the factors governing the EFL learners' preferences for employing repair strategies. It compares how repetition and self-initiated repair strategies are used by Arab and German EFL learners. More specifically, the aim of the present research is to answer the following questions:

1. Which is the most frequent repair strategy used by both groups (German and Jordanian EFL learners) in a story-retelling task: self-initiated repair or repetition?

2. Are there any significant differences in the use of repair strategies between Arab and German EFL learners? 


\section{Method}

\subsection{Participants}

The participants of this study were male and female volunteer third-year students enrolled in the Linguistics Department at Chemnitz Technical University (Germany) and the University of Jordan (Jordan). In August 2009, ten voluntary participants from each university, ranging from age 20 to 22 , performed a story-retelling task. The average number of years of prior formal English instruction for the German group was between ten and fifteen years, while it was 15 years in the case of the Jordanian participants.

\subsection{Data Collection Instrument and Data Analysis}

Two short stories were selected from 100 free short English stories for ESL learners (http://www.rong-chang.com/qa2/): Mayor Denies Hit-and-Run Charge and A School Girl Sues Her School, which were thought to be interesting, and within the proficiency level of the students, as consultions with three university professors revealed. All participants were given a printe copy of the stories to read one hour before the performance session. Using the program Audacity, the participants were individually audio-recorded in the researcher's office while retelling the stories to the researcher. The researcher used gestures, such as nodding, to show that he was following, and interested, and to encourage the participants to continue their retelling. Since real-life conversations require more interaction between speakers, the researcher also tried to interrupt the participants, using words and expressions, such as then, aha, oh my God!, Did he do that? Oh Really! and What happened then? This had a positive impact on the participants' performance, and their motivation to complete the task. The participants' production was carefully transcribed. All pauses and sound lengthenings were included in the transcript. In the transcription, every three dots represent a second's pause, which was measured with the use of a stop watch. Markee (2000) suggests that the entire speech event should be transcribed to "provide an exhaustive account of the data potentially available for analysis" (p. 105).

The researcher was interested in analysing the oral production of the participants because the interlocutor, who was the researcher of the present study himself, did not produce much discourse. Basing on markers of repair, the researcher detected repair strategies in the transcripts of the spoken discourse of the German and Arab learners of English, and then classified them into two categories: repetition and self-initiated repair. Markee (2000) identified markers of repair stating that "From a CA perspective, all repairs are likely to be signalled by various markers of incipient repair (pauses, silences, sound stretches, cut-offs and phrases like 'you know' and 'I mean'" (p. 86). First, frequencies and percentages of self initiation self repair and repetition strategies were calculated. Furthermore, to find out any statistical differences between the strategies of repair employed by the German and Jordanian EFL learners, a t-test was used.

\subsection{Reliability of Data Analysis Procedures}

In order to maximize the reliability of the researcher's classification, it was passed to three intra-raters, who are professors of Applied Linguistics at the University of Jordan. In order to make the raters' task easier, the strategies were highlighted and classified in context. That is, the whole utterance in which repetition or self-initiated repair was used was transcribed. The raters were asked to verify whether that the researcher's classification was accurate based on the definition of each strategy. If they disagree with the researcher's classification, they were asked to give an alternative classification. Their comments were taken into consideration in arriving at the final categories and frequencies.

\section{Results and Discussion}

\subsection{Overall Frequencies and Percentages}

Table 1. Frequencies and Percentages of Repair Strategy Use among the Jordanian Participants

\begin{tabular}{lll}
\hline Strategy Type & Frequency & Percentage \\
\hline Repetition & 66 & 53.65 \\
\hline Self-initiated repair & 57 & 46.35 \\
\hline Total & $\mathbf{1 2 3}$ & $\mathbf{1 0 0 \%}$ \\
\hline
\end{tabular}

As can be seen in Table 1, the Jordanian participants recorded 123 instances of repair strategies while retelling the two stories. It was observed that they tried their best to report as many events as they could; even very 
specific details were reported. This was evident in the average number of words used in their oral production, which by means of MS Office word count, was found to be 450 words per story on average. It was also observed that all the Jordanian participants used some instances of repair, either repetition or self-initiated repair. They resorted to the two strategies under investigation at the rate of 66 and 57 instances, respectively.

Table 2. Frequencies and Percentages of Repair Strategy Use among the German Participants

\begin{tabular}{lll}
\hline Strategy Type & Frequency & Percentage \\
\hline Repetition & 25 & 41.66 \\
\hline Self-initiated repair & 35 & 48.34 \\
\hline Total & $\mathbf{6 0}$ & $\mathbf{1 0 0 \%}$ \\
\hline
\end{tabular}

Table 2 above shows that the German participants used fewer strategies than the Jordanians; they employed a total number of 60 strategies of repair, representing both types. Contrary to the Jordanian participants, it was noted that the German subjects described only the key events; very specific details were not reported. It was also observed that the German learners were more generic in their story-retelling. This was manifested in the average number of words they produced, which was 260. Contrary to the Jordanian participants (Arabic speakers), the Germans used repetition less frequently ( 25 cases). Similarly, it was observed that all the participants used instances of repair, repetition and self-initiated repair.

In order to find out whether these differences were significant or not, a t-test was used. The results of this statistical analysis procedure are illustrated in Table 3. The table below shows that the Jordanian participants' mean score was 12.30, while the German participants' mean score was 6 , indicating that the Jordanians used more cases of strategies of repair. The results of the t-test (Table 3) reveal significant differences between the Jordanian and German participants' strategy use at $\alpha=.5$. This study also reveals that there are significant differences between the two groups on each strategy (self-initiated repair and repetition) at $\alpha=.05$. This might imply that the Jordanian participants used more strategies because they encountered more problems while retelling the two stories.

Table 3. t-test Analysis Results

\begin{tabular}{|c|c|c|c|c|c|c|}
\hline Strategy Type & Group & $\mathbf{N}$ & Mean & Std. Deviation & $\mathbf{T}$ & Sig. \\
\hline \multirow{2}{*}{$\begin{array}{l}\text { SELF-INITIATED } \\
\text { REPAIR }\end{array}$} & Jordanian & 10 & 5.70 & 1.42 & \multirow{2}{*}{4.40} & \multirow{2}{*}{0.00} \\
\hline & German & 10 & 3.50 & .71 & & \\
\hline \multirow{2}{*}{ REPETITION } & Jordanian & 10 & 6.60 & 1.51 & \multirow{2}{*}{8.13} & \multirow{2}{*}{0.00} \\
\hline & German & 10 & 2.50 & .53 & & \\
\hline \multirow{2}{*}{ TOTAL } & Jordanian & 10 & 12.30 & 2.83 & \multirow{2}{*}{6.76} & \multirow{2}{*}{0.00} \\
\hline & German & 10 & 6.00 & .817 & & \\
\hline
\end{tabular}

\subsection{Repetition}

Repetition was recorded when the subjects repeated some language items in order to delay the production of the following lexical item or to gain time to retrieve the required difficult item(s). A closer look at the repetition cases in the present study revealed that the most frequently employed repetition subcategories were repetitions of nouns, personal pronouns, conjunctions, prepositions, definite and indefinite articles and demonstrative pronouns.

It was noticed that the repairing segment and the repaired segment were lexically identical (repetition). The use of pauses and fillers, such as er and em indicated that the subjects encountered some difficulties in retrieving the following lexical item(s) they needed. The Jordanian participants performed 66 instances of repetition. The following excerpts were taken from the performance of the Jordanian participants. The repeated words and phrases are italicized, and every three dots mean a second's pause. 
(1) but er er $, \ldots, \ldots, \ldots$. .she may $, \ldots, \ldots$,er...find er, ..., some difficulties in er, ..., er, some difficulties in finding husband.

(2) Then the sheriff er ,..., er ..., took out the bull horn and told him er,..., what about this is ... er... this is yours?

(3) so er so er this is the whole story about Virginia.

(4) she didn't like it...er,..., her father,.., her father,.., complain,..., er,..., er ,..., a court.

(5) and er,..., all her friends ,..., and all her friends ,..., er are American ,..., are American and African,..., are American African.

Similarly, the German participants employed repetition as a strategy of repair ( 25 cases) in order to gain time, retrieve the following lexical item(s), and maintain conversation. The following excerpts (6-10), which are self-explanatory, are taken from the oral performance of the Germans, with the repeated words and phrases presented in italics.

(6) there is a witness who er who claims that he saw the mayor hit the calf.

(7) and that em ,...,..., that an A student em should have em a chance to go to every university even if she gets a $\mathrm{C}$ in the cooking class.

(8) and she the er the er the student, the principle spoke very highly of the er of the teacher.

(9) and he drove to the mayor's house er mayor's house, er er,..., and er confronted him with the accident.

(10) The second story is about a school er school girl named is Virginia Brown.

The most prominent feature of the above excerpts is that the participants stumbled during their speech although there were very few errors corrected. Levelt (1983) called this a covert error or a potential error which has been discovered before articulation. The editing expressions er and em signal that the participants thought for some time that an error might be committed in the following lexical item, or they used them because they needed more time to produce the next lexical item(s).

\subsection{Self-Initiated Repair}

In the present study, the Jordanian participants resorted to self-initiated repair on 57 occasions. In the following excerpts taken from their oral discourse, the repairing segment and the repaired segments are italicized. In excerpt 11, the speaker might have been planning to produce "The Mayor did not admit that he had hit a calf", but, due to her limited linguistic resources, she stopped after 'didn't', and started a new plan. After hesitation and some pauses, which indicate the presence of a problem, she produced "he told the sheriff that ...".

(11) er the mayor er, ..., didn't er ... er he told the sheriff that he thought he hit a speed pump er not a calf.

The speaker, in excerpt 12, produced "singing" (repairable segment), but she immediately discovered that she was making a mistake in verb tense. Therefore, she corrected it as "is singing" (repaired segment). In the speech event "She is on the volleyball team", the repairing segment "in a volleyball", was repaired by "she joined in a volleyball..., er (a 10-second pause)". It appears that the speaker was searching for the lexical item "team"; unfortunately, she could not retrieve it, as clearly manifested in her hesitation and pauses.

(12) Virginia joined many clubs,...,er..for example,...,singing, ..., she is singing,..., and er in a volleyball,..., $e r, \ldots$ she joined in a volleyball $\ldots . . \mathrm{er}, \ldots, \ldots, \ldots, \ldots, \ldots, \ldots, \ldots, \mathrm{er}, \ldots$ (10 second pause).

In excerpt 13, the size of the problem is big for this speaker, and this is evident in this short utterance, which includes two instances of self-initiated repair. First, the speaker corrected the repairing segment "child" by the repaired segment "small child". In the speech event "All her grades have been A's", the speaker paraphrased it, but while paraphrasing, she initiated the repair and corrected it. She produced "got an A's in her er... (pause)", she stopped here and executed another plan, which started with the same repairing segment "in her", but she could not complete it. Therefore, she decided again to change her plan, and started a new one after the 'er'. She abandoned her message, and started another: "in every subject she ... she took it". Then, she corrected the repairing segment, and produced "er in every subject she ...she took".

(13) It is er about er a child er small child er she er got an As in her er, ..., in her er in every subject she ,..., she took it.

The German participants in the present study, on the other hand, resorted to self-initiated repair strategy in 35 cases. For example, the speakers in the following excerpts (14-17) had a plan they wanted to execute, but due to some difficulties in retrieving the required lexical items, they repeated the repairing segment and corrected the error. In 
excerpt 14, the speaker produced the repairing segment 'bulls', then she recognized that she was making an error. Thus, she corrected it by uttering "bull horns". In excerpt 15 , the speaker discovered that she was making an error in verb tense, so she corrected the verb 'has' to 'had'.

(14) She says he is the only one with bulls er Bull horns on the front of the car.

(15) The student obviously has...had perfect grades and she was like the perfect student.

In excerpt 16 below, the speaker started with a plan which she wanted to execute "she the the the student"; however, she altered it and started a new plan where she used the phrase "the principal". The repetition phenomenon prevailing in this excerpt indicates that the speakers is encountering a communication problem.

(16) And she the the the student er the principle spoke very highly of the of the teacher.

Due to some difficulties in retrieving the required lexical items, in order to maintain conversation, the German participants sometimes altered their plan and produced a different utterance, as in excerpt 17 below. The speaker presumably wanted to say "she has some African American friends", but she could not retrieve this phrase; she produced 'she also has ..., ahh ... like her..." instead. As she discovered her error, she fixed it by planning a new utterance, and the output was "she says that some of her best friends are Afro-Americans" (repaired segment).

(17) she denies that umm it was an issue of racism um... because she also has ... ahh... like her ... she says that some of her best students are Afro-Americans umm...

\section{Discussion and Conclusion}

The results of the present study confirm the use of two types of repair: repetition and self-initiated repair by German and Jordanian EFL learners. These findings are in line with the results of previous research on strategies of repair (Rieger, 2000; Rieger, 2003; Rababah, 2001). However, it was found that there were significant differences between the two groups in terms of the frequency of strategy use. The statistical analysis presented in Tables 1-3 revealed that the Jordanian learners utilized significantly more repetition and self-initiated repair strategies in the story retelling task, when compared to the German learners' performance. This may have been due to the number of words they produced, which almost doubled that of the Germans, which could be attributed to mother tongue influence, since Arabic is described as a verbose language.

Repetition was used by both groups as an attempt made by the speaker to plan for a new utterance or to gain time to recall the next lexical item, while in self-initiated repair, the Jordanian and German participants' aim was to monitor and modify an utterance when s/he felt that $\mathrm{s} / \mathrm{he}$ made an error. Although the Germans used fewer repetition strategies, which could be attributed to the fact that they were more concise in story-retelling, i.e., they reported only the major events in both stories, the instances of repetition were found to be very similar in terms of their subcategories in the Germans' and Jordanians' performance. They were e.g. nouns, personal pronouns, prepositions, articles and demonstrative pronouns.

The study also revealed that although self-initiated repair was used by all the participants, the Jordanian EFL learners used it more frequently (cf. Table $1 \&$ Table 2). Self-initiated repair was used when the speakers encountered problems with retrieving the target language item. It was also noticed that self-initiated repair was not always successful; that is, the speakers tried to correct what they thought to be a mistake, but they did not do that successfully. This finding is thus a verification of the view that self-initiated repair is a well-organized, orderly, and rule-governed phenomenon and not a chaotic aspect of spoken discourse (Schegloff et al., 1977; Rieger, 2000).

It was also found that both groups were keen on taking the risk to transmit comprehensible messages to their interlocutor, who was the researcher in the present study. They repeated to retrieve ideas and lexical items and maintain conversation, and they repaired to produce correct forms or ideas. The participants' use of such strategies made their oral production comprehensible, despite the presence of hesitations and pauses.

The results of this study and the researcher's observations may provide some useful insights into syllabus design and language teaching. Analyzing the language teaching books, the researcher has noticed that the repair strategies and initiation techniques used by native speakers of the target language are excluded. Syllabus designers should include these repair strategies in English teaching textbooks because the use of repair is an element of natural conversation used by both native and non-native speakers. As non-native speakers of the target language do not sometimes know how to repair, if they do, they might rely heavily on transfer from their native languages (Cokal-Karadas, 2010: 158). In the language classroom, repetition and self-initiated repair should be reinforced for student-student or student-teacher classroom interaction. The realisation that these two strategies are natural in everyday conversation, that repetition performs a wide range of functions (Brody, 1986), that self-initiated repair plays a major role in producing comprehensible input (Shehadeh, 1999), and that 
comprehensible input leads to language learning (Swain, 1985) makes it important for language teachers to implement and encourage their students to resort to these two strategies. Language teachers should encourage students to be risk-takers, and use these strategies, which were classified as communication strategies (cf. Faerch \& Kasper, 1983).

\section{References}

Bada, E. (2010). Repetition as vocalized fillers and self-repairs in English and French interlanguages. Journal of Pragmatics, 42, 1680-1688. http://dx.doi.org/10.1016/j.pragma.2009.10.008

Berg, T. (1986). The aftermath of error occurrence: Psycholinguistic evidence from cut-offs. Language and Communication, 6, 195-213. http://dx.doi.org/10.1016/0271-5309(86)90023-6

Birkner, K., Henricson, S., Lindholm, C., and Pfeiffer, M. (2012). Grammar and self-repair: Retraction patterns in German and Swedish prepositional phrases. Journal of Pragmatics, 44, 1413-1433. http://dx.doi.org/10.1016/j.pragma.2012.06.003

Brody. J. (1986). Repetition as a rhetorical and conversational device in Tojolabal (Mayan). International Journal of American Linguistics, 52(3), 255-274.

Cokal-Karadas, D. (2010). Conversational repair in foreign language classrooms: A case study in a Turkish context. Eurasian Journal of Educational Research, 39, 145-160.

Hoekje, B. (1984). Processes of repair in non-native speaker conversation. ERIC.

Dascal, M. (1999). Introduction: Some questions about misunderstanding. Journal of Pragmatics, 31, 753-62.

Drew, P. (2005). Conversation Analysis' (71-102). In K. L. Fitch, \& R. E. Sanders (Eds.), Handbook of Language and Social Interaction. Mahwah, NJ: Lawrence Erlbaum.

Drew, P. (1997). 'Open' class repair initiators in response to sequential sources of troubles in conversation. Journal of Pragmatics, 28, 69-101. http://dx.doi.org/10.1016/S0378-2166(97)89759-7

Faerch, C., \& Kasper, G. (1982). Phatic, metalingual and metacommunicative functions in discourse: Gambits and repairs (pp. 71-103). In N. E. Enkvist (Ed.), Impromptu Speech: A Symposium. Åbo: Åbo Akademi.

Faerch, C., \& Kasper, G. (1983). Plans and strategies in foreign language communication. In Faerch, C., \& Kasper, G. (Eds.), Strategies in Interlanguage Communication. London.

Kernan, K. T., Sabsay, S., \& Schneider, P. (2008). Structure and Repair in Narratives of Mentally Retarded Adults. Journal of Linguistic Anthropology, 1(2), 143-164. http://dx.doi.org/10.1525/jlin.1991.1.2.143

Krahnke, K., \& Christison, M. (1983). Recent language research and language teaching principles. TESOL Quarterly, 17(4), 625-649. http://dx.doi.org/10.2307/3586617

Leonard, L. (1983). Speech selection and modification in language-disordered children. Topics in Language Disorders, 4, 28-37.

Levelt, W. J. M. (1983). Monitoring and self-repair in speech. Cognition, 14, 41-104. http://dx.doi.org/10.1016/0010-0277(83)90026-4.

Markee, N. (2000). Conversation Analysis. Lawrence Erlbaum, Mahwah, NJ.

Nagano, R. (1997). Self-repair of Japanese speakers of English: A preliminary comparison with a study by W. J. M. Levelt. Bulletin of Language Science and Humanities, 65-90.

Rababah, G. (2001). An Investigation into the Strategic Competence of Arab Learners of English at Jordanian Universities. PhD Dissertation. University of Newcastle upon Tyne, UK.

Rababah, G., \& Bulut, D. (2007). Compensatory strategies in Arabic as a second language. Poznan Studies in Contemporary linguistics, 43(2), 83-106. http://dx.doi.org/10.2478/v10010-007-0020-5

Rieger, C. (2000). Self-repair Strategies of English-German Bilinguals in Informal Conversations: The Role of Language, Gender and Proficiency. PhD Dissertation, University of Alberta.

Rieger, C. (2003). Repetitions as self-repair strategies in English and German conversations. Journal of Pragmatics, 35, 47-69. http://dx.doi.org/10.1016/S0378-2166(01)00060-1

Schegloff, E. A. (2000). Overlapping talk and the organization of turn-taking for conversation. Language in Society, 29, 1-63.

Schegloff, E. A. (2007). Sequence Organization in Interaction: A Primer in Conversation Analysis 1. Cambridge: 
Cambridge University Press.

Schegloff, E. A., Jefferson, G., \& Sacks, H. (1977). The preference for self-correction in the organization of repair in conversation. Language, 53(ii), 361-382.

Shehadeh, A. (1999). Insights into learner output. English Teaching FORUM, 37(4), 2-6.

Swain, M. (1985). Communicative competence: Some roles of comprehensible input and comprehensible output in its development. In Gass, S., \& Madden, C. (Eds.), Input in Second Language Acquisition (pp. 235-256). New York: Newbury House.

Tzanne, A. (2000). Talking at Cross-Purposes. The Dynamics of Miscommunication. Amsterdam/Philadelphia: John Benjamins.

Watterson, M. (2008). Repair of non-understanding in English in international communication. World Englishes, 27(3-4), 378-406. http://dx.doi.org/10.1111/j.1467-971X.2008.00574.x

Wood, D. (2006). Uses and functions of formulaic sequences in second-language speech: An exploration of the foundations of fluency. The Canadian Modern Language Review / La revue canadienne des langues vivantes, 63(1), 13-33. http://dx.doi.org/10.3138/cmir.63.1.13 